\title{
Avaliação de desempenho de lagoa de polimento para pós-tratamento de reator anaeróbio de manta de lodo (UASB) no tratamento de águas residuárias de suinocultura
}

\author{
[Evaluation of the performance of a polishing pond for the post-treatment of the effluent from an upflow anaerobic \\ sludge blanket (UASB) reactor treating swine wastewater] \\ L.S. Rodrigues ${ }^{1}$, I.J. Silva ${ }^{2}$, R.L.H. Santos ${ }^{3}$, D.B. Goulart ${ }^{4}$, P.R. Oliveira ${ }^{2}$, \\ M. Von Sperling ${ }^{5}$, D.O. Fontes ${ }^{2}$ \\ ${ }^{1}$ Engenheiro agrícola autônomo - Lavras, MG \\ ${ }^{2}$ Escola de Veterinária - UFMG - Belo Horizonte, MG \\ ${ }^{3}$ Médica veterinária autônoma - Belo Horizonte, MG \\ ${ }^{4}$ Aluna de graduação - EV-UFMG - Belo Horizonte, MG \\ ${ }^{5}$ Escola de Engenharia - UFMG - Belo Horizonte, MG
}

\section{RESUMO}

Avaliou-se o desempenho de uma lagoa de polimento, no tratamento de efluentes de águas residuárias de suinocultura de um reator anaeróbio de manta de lodo (UASB). O sistema foi composto de decantador, reator UASB, em escala real, e lagoa de polimento em escala experimental. As análises físico-químicas realizadas foram: temperatura, $\mathrm{pH}$, demanda bioquímica de oxigênio (DBO), demanda química de oxigênio (DQO), sólidos suspensos totais (SST) e sólidos suspensos voláteis (SSV), nitrogênio total kjedhal (NTK), nitrogênio amoniacal (N-am.) e orgânico (N-org.), fósforo total (Pt), coliformes totais e termotolerantes. A lagoa de polimento apresentou alto desempenho, com remoção média de $58,9 \%$ de DBO, $60,1 \%$ de NTK, $57 \%$ de N-am. e $95,34 \%$ de coliformes termotolerantes.

Palavras-chave: suinocultura, águas residuárias, lagoa de polimento, reator UASB

\begin{abstract}
The performance of a polishing pond for treating swine wastewater from an upflow anaerobic sludge blanket (UASB) reactor was evaluated. The system was assembled with a slat settler, followed by an $U A S B$ reactor, on a real scale, and a post-treatment pond, on a demonstration scale. The following parameters were analyzed: temperature, $p H$, biochemical oxygen demand (BOD), chemical oxygen demand (COD), total suspended solids (TSS), volatile suspended solids (VSS), total Kjedahl nitrogen (NTK), ammonia nitrogen (N-am.), organic nitrogen, total phosphorus, and total and thermotolerant coliforms. The polishing pond was highly efficient, removing an average of $58.9 \%$ of BOD, $60.1 \%$ of NTK, $57 \%$ of $\mathrm{N}$-am., and $95.34 \%$ of thermotolerant coliforms.
\end{abstract}

Keywords: swine wastewater, polishing pond, UASB reactor

\section{INTRODUÇ̃̃O}

A suinocultura constitui uma das cadeias produtivas melhor estruturadas do agronegócio brasileiro, compreendendo o terceiro maior rebanho mundial, porém sua exploração é considerada pelos órgãos de controle ambiental como uma atividade potencialmente causadora de degradação ambiental, sendo enquadrada como de grande potencial poluidor (Palhares e Calijuri, 2006).

A alta geração de resíduos provenientes da suinocultura tem como principal destino a simples disposição no solo. Esta prática faz com que, em muitas situações, tenha-se excesso de nutrientes, metais e organismos patogênicos no solo, tornando difícil a absorção na mesma taxa 
em que estas substâncias são aplicadas, acarretando lixiviação e/ou percolação desses resíduos para os corpos d'água superficiais e subterrâneos, causando poluição (Perdomo et al., 2003).

O reator anaeróbio de manta de lodo (UASB) representa um grande avanço na aplicação da tecnologia anaeróbia para o tratamento direto de águas residuárias, sejam de natureza simples ou complexa, de baixa ou de alta concentração, solúveis ou com material particulado. Como qualquer reator biológico, possui vantagens e desvantagens, no entanto sua utilização tem demonstrado ser ele o de maior sucesso entre os reatores anaeróbios até o momento (Kato et al., 1999).

Apesar das suas grandes vantagens, os reatores anaeróbios dificilmente produzem efluentes que atendem aos padrões estabelecidos pela legislação ambiental, tornando-se necessárias unidades de pós-tratamento a jusante do reator (Chernicharo, 2007).

Entre as alternativas de pós-tratamento, destacase o uso das lagoas de polimento, pelo fato de se manter, em todo o sistema, a simplicidade conceitual já assumida para os reatores anaeróbios (Von Sperling, 2002).

Quando se aplica um pré-tratamento anaeróbio eficiente, antes de se descarregar esgoto em uma lagoa, as concentrações de matéria orgânica e de sólidos suspensos são reduzidas em grande magnitude, de modo que a remoção destes constituintes, em um sistema de lagoas, será muito mais fácil e, por esta razão, pode ser efetivada com um tempo de detenção hidráulico (TDH) muito inferior (Chernicharo, 2007).

Nas lagoas de polimento, predomina um ambiente aeróbio, devido à combinação de menor demanda de oxigênio com maior produção de oxigênio, o que leva à prevalência da fotossíntese sobre a oxidação bacteriana.

Devido aos baixos TDH nos reatores anaeróbios, a remoção de organismos patogênicos é baixa nessas unidades. Neste sentido, as lagoas de estabilização e, principalmente, as de maturação podem contribuir substancialmente para uma elevada remoção. No contexto do pós-tratamento de efluentes anaeróbios, as lagoas de polimento exercem bem este papel, sendo esta uma de suas principais finalidades (Von Sperling, 2002).

Objetivou-se com este trabalho avaliar o desempenho de uma lagoa de polimento em escala piloto, instalada após o reator UASB, na remoção de matéria orgânica, nutrientes e coliformes.

\section{MATERIAL E MÉTODOS}

O trabalho foi desenvolvido no setor de suinocultura da Fazenda Experimental Professor Hélio Barbosa da Escola de Veterinária da UFMG. O sistema de tratamento (Fig. 1) foi composto por tratamento preliminar (tela), decantador e reator UASB em escala plena e uma lagoa de polimento em escala experimental, sendo que a lagoa foi construída, utilizando-se uma caixa d'água de amianto de capacidade 1000L. As dimensões da lagoa foram de $1,10 \mathrm{x}$ $1,30 \mathrm{~m}$, e profundidade de $0,65 \mathrm{~m}$.

A alimentação da lagoa foi realizada coletandose $20 \mathrm{~L} \mathrm{~d}^{-1}$ do efluente do reator UASB, transferido por meio de uma caixa de inspeção para a lagoa.

O programa de monitoramento do sistema de tratamento teve duração de 10 meses, realizado por meio de análises físico-químicas $\mathrm{e}$ bacteriológicas. Os parâmetros avaliados foram: temperatura do ar e do líquido, $\mathrm{pH}$, alcalinidade total, ácidos voláteis totais, oxigênio dissolvido (OD), demanda bioquímica de oxigênio (DBO), demanda química de oxigênio (DQO), sólidos suspensos totais (SST), sólidos suspensos voláteis (SSV), nitrogênio total Kjedhal (NTK), nitrogênio orgânico, nitrogênio amoniacal, fósforo total, coliformes totais e coliformes termotolerantes. As amostras foram coletadas três vezes por semana no afluente e efluente do decantador, do reator UASB e da lagoa de polimento.

As análises físico-químicas e bacteriológicas de rotina foram realizadas conforme descrito no Standard... (1998), exceto as análises de ácidos voláteis totais, que foram realizadas de acordo com Dillalo e Albertson (1961). 


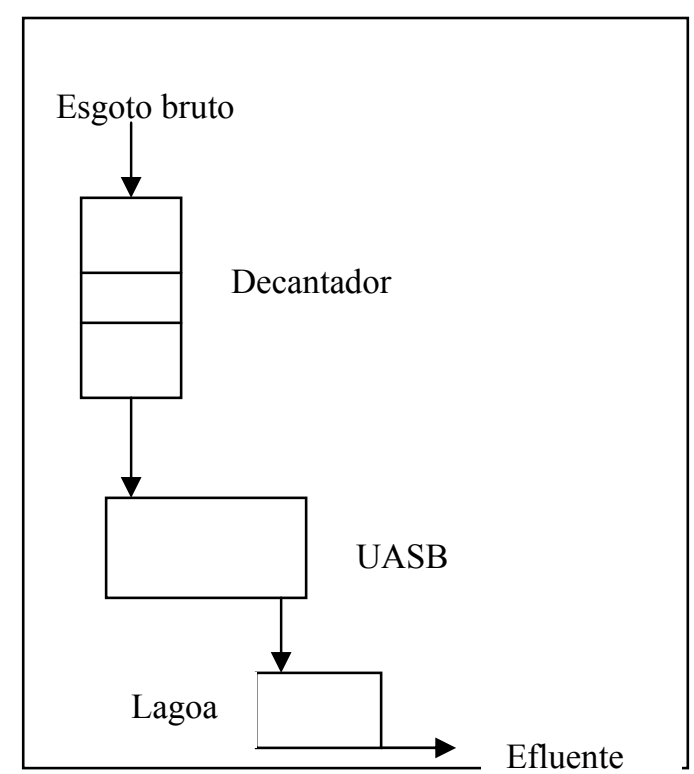

Figura 1. Croqui esquemático do sistema de uaıaııııı.

As médias de temperatura do ar foram realizadas no período da manhã por meio de um termo-higrômetro instalado junto ao sistema de tratamento. A temperatura e o $\mathrm{pH}$ do líquido foram medidos in loco, as análises de alcalinidade, ácidos voláteis total, oxigênio dissolvido e DBO foram realizados imediatamente após a coleta. As demais análises foram processadas no Laboratório de
Saneamento da Escola de Veterinária da UFMG.

\section{RESULTADOS E DISCUSSÃO}

$\mathrm{Na}$ Tab. 1, são apresentados os valores médios dos parâmetros físico-químicos no afluente e no efluente da lagoa de polimento.

Tabela 1. Média dos parâmetros físico-químicos obtidos no afluente e efluente da lagoa de polimento

\begin{tabular}{lcccccccc}
\hline & $\begin{array}{c}\mathrm{T} \\
{ }^{\circ} \mathrm{C}\end{array}$ & $\mathrm{pH}$ & $\begin{array}{c}\mathrm{DBO} \\
\mathrm{mg} \mathrm{L}^{-1}\end{array}$ & $\begin{array}{c}\mathrm{DQO} \\
\mathrm{mg} \mathrm{L}^{-1}\end{array}$ & $\begin{array}{c}\mathrm{SST} \\
\mathrm{mg} \mathrm{L}^{-1}\end{array}$ & $\begin{array}{c}\mathrm{NTK} \\
\mathrm{mg} \mathrm{L}^{-1}\end{array}$ & $\begin{array}{c}\mathrm{N}-\mathrm{am} . \\
\mathrm{mg} \mathrm{L}^{-1}\end{array}$ & $\begin{array}{c}\mathrm{Pt} \\
\mathrm{mg} \mathrm{L}^{-1}\end{array}$ \\
\hline Afluente & 22 & 7,07 & 790 & 1820 & 850 & 1900 & 1430 & 340 \\
Efluente & 19 & 7,95 & 200 & 860 & 500 & 760 & 610 & 240 \\
\hline
\end{tabular}

T: temperatura do líquido; pH: potencial hidrogeniônico; DBO: demanda bioquímica de oxigênio; DQO: demanda química de oxigênio; SST: sólidos suspensos totais; NTK: nitrogênio total Kjedhal; N-am.: nitrogênio amoniacal; Pt: fósforo total.

A lagoa de polimento apresentou uma eficiência média de remoção de DBO de 58,9\%, complementando a eficiência do sistema em $6,2 \%$, elevando a eficiência global de 91,6 para $97,8 \%$. A eficiência da lagoa e o acréscimo que proporcionou no sistema foram baixos, devido às características do efluente, que, ao chegar à lagoa, a maior parte da matéria orgânica facilmente degradada já havia sido removida pelo decantador e reator UASB, restando para a lagoa a matéria orgânica de difícil degradação.

Durante o período experimental, foram observadas pequenas oscilações nos valores de DBO na lagoa, exceto no mês de setembro, quando ocorreu um pico de concentração devido a sobrecargas hidráulicas e orgânicas ocorridas no sistema (Fig. 2). 


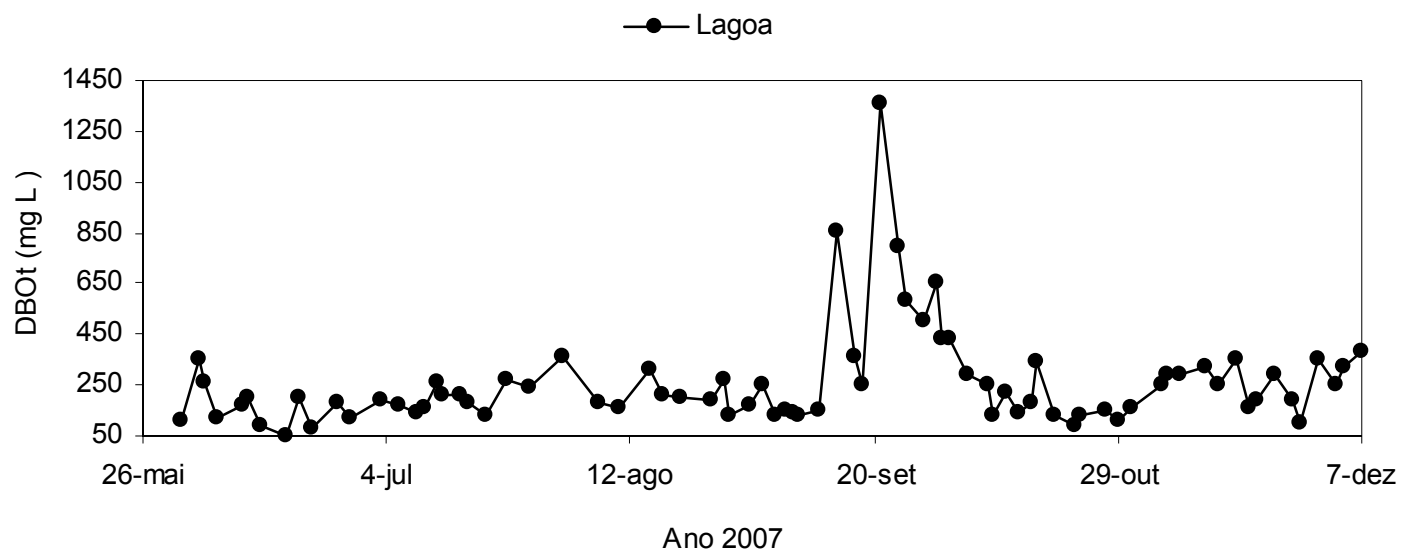

Figura 2. Variações da DBO no efluente da lagoa de polimento ao longo do período experimental.

Em relação à DQO, a lagoa apresentou uma eficiência média de 40,4\%, inferior a da DBO e também em consequência das características do efluente recebido pela lagoa.

Com relação aos sólidos, foram obtidas concentrações efluentes de SST de $500 \mathrm{mg} \mathrm{L}^{-1}$, sendo que a eficiência média da lagoa foi de
$38,1 \%$, eficiência esta baixa, devido à grande concentração de algas saindo com o efluente.

Os valores do coeficiente de remoção $(\mathrm{K})$ para a DBO e a DQO para os regimes hidráulicos de mistura completa e fluxo disperso são apresentados na Tab. 2.

Tabela 2. Valores médios de coeficiente de remoção de matéria orgânica para a lagoa de polimento

\begin{tabular}{lcc}
\hline \multicolumn{1}{c}{ Regime hidráulico } & $\mathrm{K} \mathrm{DBO}\left(\mathrm{d}^{-1}\right)$ & $\mathrm{K} \mathrm{DQO}\left(\mathrm{d}^{-1}\right)$ \\
\hline Mistura completa & 0,08 & 0,05 \\
Fluxo disperso & 0,04 & 0,02 \\
\hline
\end{tabular}

Os valores de coeficiente de remoção $K$ para DBO e DQO observados, tanto para o regime hidráulico de mistura completa como para o fluxo disperso, foram muito baixos quando comparados com os relatados por outros autores (Von Sperling, 1999; Rocha, 2002; Mascarenhas et al., 2004). Os baixos coeficientes obtidos estão relacionados às características do efluente do reator UASB, característico de matéria orgânica de mais difícil degradação e com concentrações elevadas de sólidos suspensos.

$\mathrm{Na}$ Tab. 3, são apresentadas as concentrações médias (média geométrica) e eficiências de remoção de coliformes termotolerantes, em porcentagem e em unidades logarítmicas removidas. Na Fig. 3, são apresentadas as concentrações de coliformes termotolerantes ao longo do período experimental.
Observa-se (Tab. 3) que a lagoa de polimento promoveu redução 1,33 unidades logarítmicas dos coliformes termotolerantes, valor semelhante ao do reator UASB, o que evidencia que a lagoa não teve bom desempenho para este parâmetro, já que foi dimensionada com esta finalidade. Observando a eficiência global do sistema, notase uma remoção média de 99,99\% (4 unidades logarítmicas removidas), resultando em um efluente com concentração média de coliformes termotolerantes de $1,1 \times 10^{3} \mathrm{NMP} 100 \mathrm{~mL}^{-1}$. Este valor atende a diretriz da OMS (WHO, 1989) para o uso do efluente na irrigação irrestrita, de 1 x $10^{3} \mathrm{NMP} 100 \mathrm{~mL}^{-1}$.

Os coeficientes de decaimento bacteriano para a temperatura de $20^{\circ} \mathrm{C}$ para os regimes hidráulicos de mistura completa e fluxo disperso para a lagoa de polimento foram 0,98 e $0,23 \quad\left(\mathrm{~d}^{-1}\right)$, respectivamente. 


\section{Rodrigues et al.}

Tabela 3. Valores de concentrações e eficiências médias de remoção de coliformes termotolerantes

\begin{tabular}{ccccccccc}
\hline \multicolumn{3}{c}{ Concentrações médias de coliformes } & \multicolumn{5}{c}{ Eficiências médias de remoção de coliformes } \\
\multicolumn{2}{c}{ termotolerantes (NMP 100 $\left.\mathrm{mL}^{-1}\right)$} & \multicolumn{5}{c}{ termotolerantes } \\
\hline Afluente & Efluente & Efluente & Efluente & Eficiência & Dec. & UASB & Lagoa & Global \\
& Dec. & UASB & Lagoa & & & & & \\
$5 \times 10^{7}$ & $2 \times 10^{6}$ & $4,2 \times 10^{4}$ & $1,1 \times 10^{3}$ & $\%$ & 88,95 & 94,22 & 95,34 & 99,99 \\
& & & & Unid. log & 0,95 & 1,24 & 1,33 & 4 \\
\hline
\end{tabular}

UASB: reator anaeróbio de fluxo ascendente e manta de lodo; NMP: número mais provável.

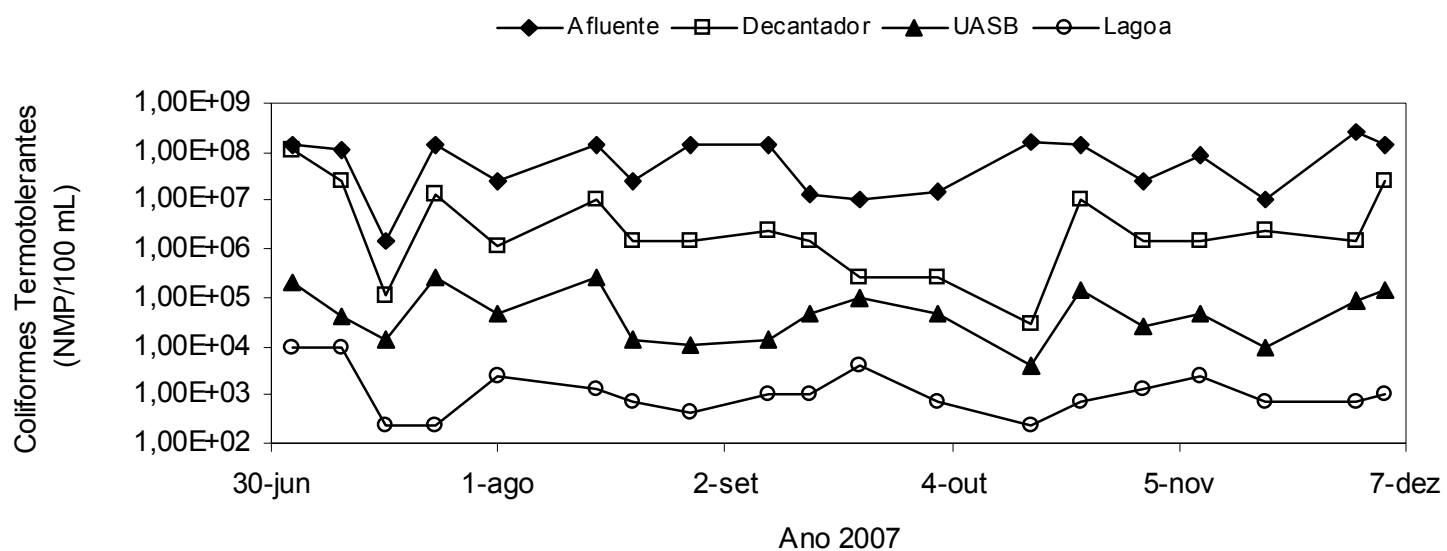

Figura 3. Variações de coliformes termotolerantes no afluente e efluente do decantador, reator UASB e na lagoa de polimento ao longo do período experimental.

Aplicando as fórmulas de $\mathrm{K}_{\mathrm{b}}$ obtidas por Von Sperling (2002) para 33 lagoas facultativas e de maturação no Brasil (1) e para 82 lagoas no Brasil e no mundo (2), foram obtidos valores de $\mathrm{K}_{\mathrm{b}}$ de 0,39 e $0,93 \mathrm{~d}^{-1}$, respectivamente.

$\mathrm{K}_{\mathrm{b}}($ disperso $)=0,917 * \mathrm{H}^{-0,877} * \mathrm{t}^{-0,329}(33$ lagoas no Brasil)

$\mathrm{K}_{\mathrm{b}}($ disperso $)=0,542 * \mathrm{H}^{-1,259}(82$ lagoas no Brasil e no mundo)

Os valores de $\mathrm{K}_{\mathrm{b}}$ encontrados neste trabalho foram menores que os obtidos por meio das equações 1 e 2 . Isto pode ser explicado pelo comportamento da lagoa, que não apresentou vários fatores de forma otimizada necessários para uma remoção eficiente dos coliformes termotolerantes, tais como $\mathrm{pH}$ elevado, alta concentração de OD, geometria da lagoa, como relata Von Sperling (2005).

$\mathrm{Na}$ Tab. 5, são mostrados os valores médios de eficiência de remoção de NTK, nitrogênio amoniacal e fósforo. Verificou-se redução da concentração de NTK ao longo do sistema de tratamento, com concentrações médias no efluente final de $760 \mathrm{mg} \mathrm{L}^{-1}$. Para o N-am., observou-se aumento na concentração do afluente para os efluentes do decantador e reator UASB e com redução na lagoa de polimento, com valor médio no efluente final de $610 \mathrm{mg} \mathrm{L}^{-1}$.

Tabela 5. Eficiências médias de remoção de nutrientes durante o período experimental

\begin{tabular}{lcccc} 
& \multicolumn{3}{c}{ Eficiência em cada unidade (\%) } & \\
\cline { 2 - 4 } Parâmetro & \multirow{2}{*}{ Eficiência global (\%) } \\
\cline { 2 - 4 } & Decantador & Reator UASB & Lagoa de polimento & \\
\hline NTK & 19,3 & $-9,8$ & 60,1 & 65 \\
N-am. & $-62,3$ & $-30,1$ & 57 & 11,1 \\
Fósforo & 27,9 & 26,4 & 29,8 & 62,2 \\
\hline
\end{tabular}


As eficiências negativas de $\mathrm{N}$-am. mostraram que houve aumento da concentração desse parâmetro no decantador e no reator UASB. Esse aumento ocorre devido ao processo de amonificação, que consiste na conversão da matéria nitrogenada orgânica em amônia. Ao se comparar a eficiência de remoção de NTK e Nam. do decantador e do reator UASB com a da lagoa de polimento, nota-se que a lagoa foi responsável pela remoção desses dois parâmetros, porém a eficiência global foi baixa.

Para o fósforo total não houve remoção significativa em nenhuma das unidades, o que fez com que o efluente final apresentasse concentrações elevadas deste elemento.

\section{CONCLUSÕES}

A lagoa de polimento como pós-tratamento de efluentes do reator UASB tratando efluentes de suinocultura em célula única apresentou baixa eficiência na remoção de matéria orgânica, coliformes e fósforo total, sendo eficiente apenas na remoção de nitrogênio.

\section{AGRADECIMENTOS}

Ao Conselho Nacional de Desenvolvimento Científico e Tecnológico (CNPq), pela bolsa de doutorado concedida, e à Fundação de Amparo a Pesquisa de Minas Gerais (FAPEMIG), pelo apoio financeiro.

\section{REFERÊNCIAS BIBLIOGRÁFICAS}

CHERNICHARO, C.A.L. Princípios do tratamento biológico de águas residuárias: reatores anaeróbios. 2.ed. Belo Horizonte: DESA-UFMG, 2007. v.5, 379p.

DILALLO, R.; ALBERTISON, O.E. Volatile acids by direct titration. J. Water Pollut. Control Fed., v.33, p.356-365, 1961.

HEALTH guidelines for the use of wastewater in agriculture and aquaculture: report of a WHO scientific group. Geneva: World Health Organization, 1989 (Technical reports series, n.778)
KATO, M.T.; ANDRADE NETO, C.O; CHERNICHARO, C.A.L et al. Configurações de reatores anaeróbios. In: CAMPOS, J.R. Tratamento de esgotos sanitário por processos anaeróbios e disposição controlada no solo. Rio de Janeiro: ABES, 1999. p.53-99.

MASCARENHAS, L.C.A.; VON SPERLING, M.; CHERNICHARO, C.A.L. Avaliação do desempenho de lagoas de polimento rasa, em série, para o pós-tratamento de efluentes de reator UASB. Eng. Sanit. Amb., v.9, p.45-54, 2004.

PALHARES, J.C.P.; CALIJURI, M.C. Impacto de sistemas de produção suinícola na qualidade dos recursos hídricos. Concórdia: Embrapa Suínos e Aves, 2006. 2p.

PERDOMO, C.C.; OLIVEIRA, P.A.V.; KUNZ, A. Sistemas de tratamento de dejetos de suínos: inventário tecnológico. Concórdia: Embrapa Suínos e Aves, 2003. 83p.

ROCHA, N.E.P. Avaliação de um sistema de tratamento de esgotos constituído de reator UASB e lagoa facultativa, em escala real. 2002. 147f. Dissertação (Mestrado em Engenharia Sanitária e Ambiental) - Escola de Engenharia, Universidade Federal de Minas Gerais, Belo Horizonte.

STANDARD methods for the examination of water and wastewater. 20.ed. Washington: APHA/AWWA/WEF, 1998.

VON SPERLING, M. Performance evaluation and mathematical modelling of coliform die-off in tropical and subtropical waste stabilization ponds. Water Res., v.33, p.1435-1448, 1999.

VON SPERLING, M. Lagoas de Estabilização. 2.ed. Belo Horizonte: DESA-UFMG, 2002. 196p. (Série: Princípios do tratamento biológico de águas residuárias, v.3).

VON SPERLING, M. Introdução à qualidade das águas e ao tratamento de esgotos. 3.ed. Belo Horizonte: DESA-UFMG, 2005. 452p. (Série: Princípios do tratamento biológico de águas residuárias, v.1). 